\title{
Suicidal behaviour in old age - results from the lbadan study of ageing
}

\author{
Akin Ojagbemi $^{1 *}$, Bibilola Oladeji ${ }^{1}$, Taiwo Abiona ${ }^{2}$ and Oye Gureje ${ }^{1}$
}

\begin{abstract}
Background: An important reason for the high risk of suicide in the elderly is the determination with which they act out their suicidal thoughts. Early identification of suicidal behaviours in the elderly is therefore important for suicide prevention efforts in this population.

Method: Data are from the Ibadan Study of Ageing (ISA), a household multi-stage probability sample of 2149 Yoruba Nigerians aged 65 years or older conducted between 2003 and 2004. We used the third version of the World Health Organization (WHO) Composite International Diagnostic Interview (CIDI) to explore suicidal experiences and behaviours. In this report, only those experiences or behaviours reported to have occurred after the age of 65 years are the focus of analysis. Derived weights were applied to the data in accordance with the study design and associations were explored using logistic regression. The results are presented as odds ratios (ORs) with $95 \%$ confidence intervals.
\end{abstract}

Result: In all, 4.0\% (95\% C.I= 3.1-4.2) of the subjects had suicidal ideation occurring after the age of 65 years, while $0.7 \%$ (95\% C.I=0.4-1.3) and 0.2\% (95\% C.I= 0.1-0.4) reported suicidal plans and attempts, respectively. There was a significantly elevated likelihood of suicidal ideation among persons who had experienced spousal separation through death or divorce (O.R=4.9., 95\% C.I=1.5-15) or who were residing in rural settings (O.R=2.5, 95\% C.I=1.3-4.8).

Conclusion: Suicidal ideation is common among the elderly. About $20 \%$ and $6 \%$ of those with ideation proceed to plans and attempts, respectively. Circumstances of social isolation and exclusion are important correlates of suicidal behaviour in the elderly.

Keywords: Suicide, Suicidal ideation, Aged, Social isolation

\section{Background}

Suicide is the most common and arguably the most important psychiatric emergency. It is defined by the World Health Organization (WHO) as "the act of killing oneself deliberately initiated and performed by the person concerned in the full knowledge or expectation of its fatal outcome" [1]. It was the cause of $1.8 \%$ of the world's 54 million deaths in 1998 [2], and an estimated 1 million death in the year 2000 [3]. Over 10 times the number of completed suicides is often reported for attempts. The worldwide incidence of suicide increases with age, with the rate of suicide in those aged over 75 years reaching up to twice or three times the rate in those younger than 25 years in most countries [4-6].

\footnotetext{
* Correspondence: drakinjagbemi@yahoo.com

${ }^{1}$ Department of psychiatry, College of Medicine, University of Ibadan, P.M.B 5017 (GPO) Ibadan, Nigeria

Full list of author information is available at the end of the article
}

Therefore, older adults are at a substantial risk of dying by suicide compared to the younger age categories. As reported by the WHO for 10 countries and a report from South-India, this pattern may be more common in developing countries $[7,8]$. The proportion of completed suicide among suicide attempters is also higher in this age category, with 1 suicide reported for every 4 attempts in older adults compared to about 1 completed suicide out of 12 attempts in the general population [9]. For these reasons, suicidal behaviour in the elderly is a major public health concern.

Suicide is a complex phenomenon. It is difficult to predict precisely, and has numerous associated factors which may be biological, psychosocial or an inter-play of these factors [9]. But suicidal ideation, suicidal attempts and actual suicide frequently occur on a continuum. Thus, suicidal thoughts are frequently the first step in

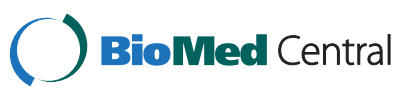


the process of eventual suicide $[10,11]$, and the elderly who has suicidal ideation may be more likely to act out their suicidal intentions through more determined and lethal techniques [12]. Therefore suicidal behaviours such as ideation and plans have variously been considered as pointers to imminent suicide [13]. Elderly persons with suicidal intention are less likely to communicate this to people around them [14]. Even when intentions have been communicated, there is evidence that such are often difficult to understand or to deal with [15]. Epidemiological studies may provide useful information about the predictors of suicidal behaviours and the transition from one behaviour to another. Such studies are yet to be conducted among elderly persons living in sub-Saharan Africa. We report on a large community-based study of suicidal behaviour among elderly persons in Nigeria.

\section{Method}

The Ibadan Study of Aging (ISA) is a community-based longitudinal survey of the mental and physical health status of elderly persons (aged 65 years and over). Its methodology has been described in full elsewhere $[16,17]$ and only a brief account is provided here. The study was conducted in the Yoruba-speaking areas of Nigeria, consisting of eight contiguous states in the south-western and northcentral regions (Lagos, Ogun, Osun, Oyo, Ondo, Ekiti, Kogi and Kwara). These states account for about $22 \%$ of the Nigerian population (approximately, 25 million people). The baseline survey, on which the present report is based, was conducted between November 2003 and August 2004.

\section{Sample}

We selected one respondent per household using a multi-stage stratified area probability sampling of households. When more than one elderly person was eligible for study, (eligibility criteria were being aged 65 years or older and fluent in the language of the study, Yoruba), the Kish table selection method was used to select the one respondent [18]. Respondents were informed about the study, invited to participate, but also assured of their right to decline. Participants were those who provided consent, mostly verbal, either because of illiteracy or by choice, before interviews were conducted. On the basis of this selection procedure, face-to face interviews were carried out on 2152 respondents (of which 2149 were complete), giving a response rate of $74.2 \%$. Nonresponse was predominantly due to non-availability after repeated visits $(14 \%)$, interviewers unable to trace the original address (4\%), death (3\%), and physical incapacitation (2\%) and rarely due to refusal (2\%).

The survey was approved by the University of Ibadan/ University College Hospital, Ibadan Joint Ethical Review Board.

\section{Measures}

Suicidal behaviour was assessed with the $3^{\text {rd }}$ version of the Composite International Diagnostic Interview (CIDI 3.0) [19]. The CIDI first lists three possible experiences: suicidal ideas (described as the presence of serious thoughts of committing suicide), plans (described as a report of a serious plan of committing suicide) and attempts (described as the occurrence of a serious attempt at committing suicide). The interview first explores the lifetime experience of each outcome and, if the subject answers in the affirmative, questions are then asked about the age of the subject at the first ever experience, the last experience and whether the respondent currently has the experience. The subject is further asked to state the number of times each event has ever occurred and if suicidal attempt resulted in some injury or needed medical attention. If the subject admits to having made suicide attempt, the interviewer asks whether the attempt was really serious and the subject survived only as a matter of luck or the subject either simply wanted to attract attention or used a suicide method knowing it was not fool-proof. Only suicidal experiences or behaviours that occurred after the age of 65 are included in this report.

\section{Depression}

Depression was assessed with the depression module of the CIDI. Diagnosis was based on the criteria of the Diagnostic and Statistical Manual of Mental Disorders, Fourth Edition (DSM-IV) [20]. DSM-IV organic exclusion rules were imposed in making the diagnosis of depression.

\section{Social network}

Social network was assessed with the CIDI. The relevant items enquire about the frequency of respondent's contact with family members who do not live with the respondent and frequency of contact with friends. In this report, we have dichotomize the responses to contacts that are less than once in six months to those more than once in six months.

\section{Chronic physical health conditions Chronic health conditions}

A checklist of chronic physical and pain conditions was included in the ISA. Respondents were asked if they had any chronic respiratory conditions (asthma, tuberculosis, other lung disease), cardiovascular conditions (high blood pressure, heart disease, heart attack, stroke), cancer, diabetes, or epilepsy. Respondents were asked whether they had experienced each of the symptombased conditions in the previous 12 months. The checklist also ascertained the presence of any chronic pain. These included back or neck pain, arthritis, frequent 
headaches, and a general category of chronic pain in any other body parts.

All the instruments used in the ISA were translated using iterative back-translation method. As part of the translation process, all the instruments used were subjected to cultural adaptation. Thus, for example, the list of household items included items common in the culture.

\section{Data analysis}

The prevalence of each of the three suicidal behaviours, ideation, plan and attempt, is presented. Associations with socio-economic variables were explored using logistic regression and the results are presented as odds ratios (ORs) with 95\% confidence intervals. We used a validated method of estimating economic status of elderly persons in low income settings by obtaining information on the possession of 21 household and personal items such as chairs, clock, bucket, radio, television set, fans, stove or cooker, car, telephone, etc. [21]. We next categorized each respondent's economic status by relating their total possessions to the median number of possessions of the entire sample. The resulting categories are low for a ratio 0.5 or less to the median, low-average for a ratio of $0.5-1.0$, high-average for $1.0-2.0$, and high if the ratio is over 2.0. Residence was classified as rural (less than 12,000 households), semi-urban (12,000 - 20,000 households) and urban (greater than 20,000 households).

The analysis took account of the stratified multistage sampling procedure and the associated clustering by applying weights as appropriate. We made adjustment for differences between the sample and the total Nigerian population by applying post-stratification to the target sex and age range. The weight so derived was normalized to reset the sum of weights back to the original sample size of 2149. To take account of the complex sample design and weighting, we used the jacknife replication method implemented with the STATA statistical package to estimate standard errors for proportions [22]. Predictor factors for each suicidal behaviour were explored with logistic regression analysis [23] and the results are presented as odds ratios (OR's) with 95\% confidence intervals (CI's), and all the Cl's are adjusted for design effects. All analyses were conducted with the STATA statistical package.

\section{Results}

\section{Characteristics of subjects}

There were 992 males (46.2\%) and 1157 (53.8\%) females in the study sample. The mean age of the cohort was $75.06 \pm 9.2$ years. Men were significantly younger with a mean age of $74.27 \pm 9.2$ years, compared to a mean age of $75.74 \pm 9.2$ years for women $(\mathrm{p}<0.001)$. One thousand one hundred and eighty four subjects (55.1\%) had no formal education, while $533(24.8 \%)$ had up to 6 years of formal education and the remaining 432 (20.1\%) subjects had more than 6 years of formal education. Primary school education lasts for 6 years in Nigeria and this is expected to make one literate. Majority of the subjects, 2,095 (97.5\%), had a religious affiliation. One thousand four hundred and twenty five (66.3\%) subjects lived in urban or semi-urban locations, while the remaining 724 (33.7\%) were domiciled in rural locations. One thousand and eighty subjects $(50.3 \%)$ were currently in a marital relationship, while 1069 (49.7\%) were not, with almost all being widowed. One thousand five hundred and fifty three $(72.3 \%)$ subjects lived in houses with mud floor, while the remaining 596 (27.7\%) lived in houses with a hard floor design. A lifetime diagnosis of depression was made in $551(25.6 \%)$ of the subjects in the study sample. The distribution of the economic groups as well as other characteristics of the subjects are shown in Table 1.

\section{Frequency of suicidal behaviour}

In all, 99 (4.0\%) subjects had experienced suicidal ideation, while $20(0.7 \%)$ of them reported a history of suicidal plans. Six $(0.2 \%)$ subjects reported a previous attempt at suicide.

Tables 2 and 3 show the comparison of the characteristics of subjects with the 3 main suicidal behaviours: ideation, plan, and attempt. There was a linear relationship between residence and risk of suicidal ideation: compared to respondents residing in urban areas, those in semi-urban areas had a (non-significant) increase in risk while there was an almost 3-fold increase in risk for respondents residing in rural areas (Table 3). The associations between suicidal behaviour and age, sex or level of education were not significant. Similarly, the relationship between suicidal behaviour and economic status was not significant. However subjects who were ever, but no longer, married, mainly through death of their spouses, were about 5 times more likely to have suicidal plans compared to those who remained married (O. $\mathrm{R}=4.9$. ., 95\% C.I $\mathrm{I}$ 1.5-15) (Table 3).

\section{Discussion}

To our knowledge this is the first report of suicidal behaviour among community dwelling elderly persons in sub-Saharan Africa. We sought to identify the prevalence of three behaviours which are known to occur in a continuum between normality and actual suicide. In this study about 1 in 20 elderly persons had experienced suicidal thoughts since they attained the age of 65 years while about 1 in 100 had made suicidal plans during this period. Given that the mean age of the sample at assessment was about 75 years, the suggestion is that these events had occurred over a period of about 10 years. The three reported behaviours provided a pattern that is 
Table 1 Characteristics of subjects

\begin{tabular}{|c|c|c|}
\hline Characteristics & Number & Percentage \\
\hline \multicolumn{3}{|l|}{ Age group (years) } \\
\hline $80+$ & 657 & 30.6 \\
\hline $75-79$ & 295 & 13.7 \\
\hline $70-74$ & 495 & 23.0 \\
\hline $65-69$ & 702 & 32.7 \\
\hline Mean (SD) & $75.06(9.2)$ & \\
\hline \multicolumn{3}{|l|}{ Gender } \\
\hline Male & 992 & 46.2 \\
\hline Females & 1157 & 53.8 \\
\hline \multicolumn{3}{|l|}{ Years of formal education } \\
\hline 0 & 1184 & 55.1 \\
\hline $1-6$ & 533 & 24.8 \\
\hline$>6$ & 432 & 20.1 \\
\hline \multicolumn{3}{|l|}{ Marital group } \\
\hline Married & 1080 & 50.3 \\
\hline Separated/Widowed/Divorced & 1069 & 49.7 \\
\hline \multicolumn{3}{|l|}{ Economic group } \\
\hline (High) & 224 & 10.4 \\
\hline (High-average) & 495 & 23.0 \\
\hline (Low-average) & 763 & 35.5 \\
\hline (Low) & 667 & 31.0 \\
\hline \multicolumn{3}{|l|}{ Residence } \\
\hline Urban & 555 & 25.8 \\
\hline Semi-urban & 870 & 40.5 \\
\hline Rural & 724 & 33.7 \\
\hline \multicolumn{3}{|l|}{ Quality of house floor } \\
\hline Earth floor & 1553 & 72.3 \\
\hline Hard floor & 596 & 27.7 \\
\hline Religious & 2095 & 97.5 \\
\hline Contact with family & 2054 & 95.6 \\
\hline Contact with friends & 1809 & 84.2 \\
\hline Lifetime depression & 551 & 25.6 \\
\hline Presence of chronic medical conditions & 628 & 29.2 \\
\hline Presence of chronic pain & 1700 & 79.1 \\
\hline
\end{tabular}

not uncommon: thus while about $20 \%$ of persons with ideation in old age had made a plan, the proportion who had made an attempt among ideators during the period was $6 \%$. A somewhat similar pattern has also been reported in an earlier study in the general population of Nigerians above the age of 18 years [24].

Estimates of suicidal ideation vary widely across studies depending on the methodology of the study, the time frame considered, or the comprehensiveness of the assessment instrument. Thus, studies of community dwelling older adults from other parts of the world report
Table 2 The distribution of suicidal behaviour according to the characteristic of subjects

\begin{tabular}{|c|c|c|c|}
\hline Characteristics & $\begin{array}{l}\text { Ideation } \\
\text { n. (\%) }\end{array}$ & $\begin{array}{l}\text { Plan. } \\
\text { n (\%) }\end{array}$ & $\begin{array}{l}\text { Attempt } \\
\text { n (\%) }\end{array}$ \\
\hline \multicolumn{4}{|l|}{ Age group (years) } \\
\hline $80+$ & $32(4.3)$ & $11(1.4)$ & $3(0.5)$ \\
\hline $75-79$ & $17(4.7)$ & $1(0.5)$ & $0 .(0.0)$ \\
\hline $70-74$ & $28(4.7)$ & $4(0.6)$ & $2(0.2)$ \\
\hline $65-69$ & $22(3.0)$ & $4(90.7)$ & $1(0.1)$ \\
\hline \multicolumn{4}{|l|}{ Gender } \\
\hline Male & $39(0.7)$ & $2(0.2)$ & $1(0.1)$ \\
\hline Females & $60(4.5)$ & $18(1.5)^{*}$ & $5(0.3)$ \\
\hline Total & $99(4.0)$ & $20(0.7)$ & $6(0.2)$ \\
\hline \multicolumn{4}{|l|}{ Years of formal education } \\
\hline $01-6$ & $51(3.9)$ & $11(0.8)$ & $2(0.1)$ \\
\hline $7-12$ & $29(4.4)$ & $4(0.7)$ & $2(0.3)$ \\
\hline \multirow[t]{2}{*}{$13+$} & $10(3.8)$ & $3(1.2)$ & $1(0.2)$ \\
\hline & $9(4.0)$ & $2(0.2)$ & $1(0.1)$ \\
\hline \multicolumn{4}{|l|}{ Marital group } \\
\hline Married & $44(3.4)$ & $5(0.3)$ & $3(0.1)$ \\
\hline Separated/Widowed/divorced & $55(5.0)$ & $15(1.5)^{* *}$ & $3(0.3)$ \\
\hline \multicolumn{4}{|l|}{ Economic group } \\
\hline High & $8(3.6)$ & $2(0.3)$ & $1(0.3)$ \\
\hline High-average & $22(3.8)$ & $3(0.6)$ & $0(0.0)$ \\
\hline Low-average & $43(4.6)$ & $10(0.9)$ & $5(0.4)$ \\
\hline Low & $26(3.6)$ & $5(0.9)$ & $0(0.0)$ \\
\hline \multicolumn{4}{|l|}{ Residence } \\
\hline Urban & $16(2.5)$ & $5(0.8)$ & $2(0.2)$ \\
\hline Semi-urban & $41(3.4)$ & $9(0.8)$ & $3(0.2)$ \\
\hline Rural & $42(6.1)^{* *}$ & $6(0.7)$ & $1(0.1)$ \\
\hline \multicolumn{4}{|l|}{ Quality of house floor } \\
\hline Earth floor & $74(4.2)$ & $17(1.0)$ & $5(0.2)$ \\
\hline Hard floor & $25(3.6)$ & $3(0.3)$ & $1(0.1)$ \\
\hline Religious & $97(4.0)$ & $20(0.8)$ & $6(0.2)$ \\
\hline Contact with family & $96(4.0)$ & $19(0.7)$ & $6(0.2)$ \\
\hline Contact with friends & $89(4.2)$ & $18(0.7)$ & $6(0.2)$ \\
\hline Lifetime depression & 551 & 25.6 & $1(0.2)$ \\
\hline
\end{tabular}

${ }^{*}=p<0.05,{ }^{* *}=p<0.01$.

that suicidal ideation occur at rates that range between $2.16 \%$ and $17 \%$ [25]. Direct comparison with other large surveys is difficult since our assessment of suicidal behaviour was specifically made on the period since the respondents attained the age of 65 years, rather than over the entire lifetime. Also, we cannot be sure of the extent to which reluctance to report these behaviours might have affected our rates. Suicidal behaviours still carry a significant level of stigma in the cultural setting of our study. However, our results show a trend similar 
Table 3 Predictors of suicidal behaviour among subjects

\section{Characteristics}

Age group (years)

$80+$

$75-79$

$70-74$

65-69

Gender

Male

Females

$0.8(0.5-1.5)$

\section{Marital group}

Married

Separated/Widowed/Divorced

$1.5(0.9-2.5)$

Years of formal education

$$
13+
$$

$7-12$

$1-6$

0

\section{Economic group}

High

High-average

1

$1.0(0.5-2.0)$

$1.1(0.4-3.0)$

$1.0(0.5-2.1)$

Low-average

Low

\section{Residence}

Urban

Semi-urban

Rural

\section{1}

$1.1(0.4-3.1)$

$1.3(0.5-3.5)$

$1.0(0.4-2.6)$

\section{1}

$1.3(0.7-2.7)$

$2.5(1.3-4.8)$

Quality of house floor

Earth floor

Hard floor

1

$0.9(0.5-1.5)$

1

$0.8(0.3-2.1)$

1

$0.7(0.2-2.8)$

\section{1}

$0.6(0.3-1.2)$

$1.1(0.5-2.2)$
Plan (n=20) O.R 56789=(95\% C.I)

Attempt (n=6) O.R (95\% C.I)

1

$0.3(0.0-3.2)$

$-(-)$

$0.4(0.1-1.6)$

$0.4(0.1-2.7)$

$0.590 .1-1.7)$

$0.2(0.1-2.1)$

1

$0.2(0.0-0.8)$

$0.2(0.0-2.5)$

$4.9(1.5-15.7)$

$2.6(0.5-14.5)$

1

$5.3(0.7-39.1)$

$3.0(0.4-22.10$

$1.6(0.1-28.3)$

$3.5(0.4-28.6)$

$1.9(0.2-22.4)$

$0.8(0.1-10.1)$

\section{1}

$1.5(0.2-12.7)$

$-(-)$

$2.4(0.4-14.8)$

$1.4(-)$

$2.5(0.4-15.3)$

$-(-)$

1

$1.0(0.3-3.9)$

$0.8(0.0-5.7)$

$1.0(0.2--4.9)$

$0.5(0.0-5.6)$

\section{1}

$0.3(0.1-1.1)$

1

$0.5(0.1-4.9)$

1

$4.1(0.6-30.7)$

$-(-)$

1

$-(-)$

$-(-)$

\section{1}

$1.2(0.2-7.2)$

$-(-)$

$1.6(0.5-4.8)$

$0.8(0.1-7.9)$
1 
to that reported among community dwelling older people in previous studies conducted in the West [26,27]. However, we note that suicidal ideation in this elderly sample is much higher than in the general Nigerian adult population in which a figure of $3.2 \%$ has been reported over the lifetime in a community sample with a mean age of about 35 years [24]. This finding suggests that old age, at least in the country setting of our study, is a significantly stressful period of life and a risk period for suicidal behaviour. The observation is in consonance with a previous report from our group suggesting one of the highest rates of major depression, both current and lifetime, among elderly persons anywhere [17]. Although most people with suicidal ideation will not progress to suicidal attempt, the older adult is however more likely to make determined effort at progressing through to actual suicide using the most lethal methods compared to younger subjects [12]. The fact that only $0.2 \%$ of our sample admitted to have made a lifetime suicidal attempt does not contradict this evidence. Since we do not have information about those who might have committed suicide in old age, the possibility exists that perhaps our observation only reflects the fact that only those who survived an attempt were alive to tell the story of their attempt. Furthermore, cultural issues about admitting to previous suicidal attempts may have affected the rates of attempted suicide reported in this study.

We also sought to identify the predictors of suicidal behaviours in this population. Living in a rural location predicted the occurrence of suicidal ideation, while being separated either through death or divorce predicted suicidal planning. In the period before the actual suicide, older people are known to experience various kinds of losses that heavily burden them. The loss of a partner has been particularly linked to an increased risk of suicide, especially in men [28-30]. Spousal loss reduces the amount of social support available to the elderly and thus increases the likelihood of social isolation. It has been argued that increased likelihood of social isolation among the elderly compared to younger persons is one of the reasons for the greater risk of suicide in the former [31]. Social isolation also predisposes to depression, a major risk factor for suicide $[27,30]$. Social isolation as well as exclusion may also explain why, in this study, living in a rural location predicted suicidal ideation. Although it has previously been argued that social isolation is more common in large populations [32], the circumstances leading to social isolation in the elderly in contemporary Africa may be slightly different. For instance, in Nigeria as in many low income countries, the young and able bodied individual drift from rural areas to urban centres seeking better economic opportunities, leaving behind a population of older persons in the rural areas. The result is a reduction of the social network available to older persons. Furthermore, in Nigeria as in other sub-Saharan countries going through social changes, there is a gradual but continuous erosion of the traditional extended family system. Typically, rural areas are deprived of social amenities and opportunities for recreation. When social amenities are available, they are often not tailored to the needs of the older person. The pattern of the relationship between rural dwelling and suicidality has been reported in the general population of many countries $[33,34]$. This appears to be in keeping with the theory of Durkheim in which poor social integration leads to increased suicide in the population [7]. Depression has often been reported in the literature as the most important predictor of suicidal behaviour in older adults, especially given its relationship with other risk factors such as social isolation, disability and illness $[27,30,35]$. However lifetime depression was not a significant predictor of suicidal behaviour in this study. One reason for this could be due to the use of different timeframes for the two measures: lifetime for depression and old age for suicidal behaviour. Perhaps a different pattern might have been observed if depression since age 65 years was examined. The possibility that recall bias might have affected the assessment of lifetime depression is also a plausible factor. Also, because of the cross-sectional nature of the data, we were unable to clearly differentiate depressive episodes occurring before suicidal behaviour, the variable of interest, from those occurring after. The effect of this would be to introduce a lot of "noise" to the examination of the association with the resultant loss of statistical power. For these reasons, we could not rule out the potential role of depression in predicting suicidality in our sample. Nevertheless, some similarly designed studies have reported that only a minority of persons with suicidal thoughts have depression symptoms sufficient for the diagnosis of a major depressive disorder even though they may have depressed mood and some other associated symptoms $[11,36]$. This finding reflects the importance of several other variables apart from depression in the complex process of suicidality.

In interpreting the results of our study, it is important to bear in mind its limitations. These include its reliance on a retrospective measure of suicidality and depression, as well as the cross-sectional nature of the study. As noted earlier, stigma around the topic of suicide is a potent factor in the population in which our study was conducted and may have resulted in conservative estimates of suicidal behaviour. Nevertheless, the findings are novel in so far as they present the picture of an important public health issue in this under-studied population.

\section{Conclusions}

Suicidal ideation is common in the elderly, and it would appear from this study that suicidality in this age group 
occurs in the same spectrum of continuity that has been reported in other age categories, where suicidal ideations are the first step towards eventual suicide. Life events and other factors that lead to e social isolation in the elderly are important predictors of suicidal behaviour in this population. Suicide prevention efforts should include provision of opportunities for participation of the elderly in social and recreational activities in their communities.

\section{Competing interests}

None of the authors have a competing interest.

\section{Authors' contributions}

AA produced the first draft of the manuscript, revised the final draft and approved it for publication, BO was involved in the conception of this work, revised the final draft of the manuscript and approved for publication, TA carried out the statistical analyses and approved for publication, and OG conceived the work, procured funds, produced the first draft, revised the final draft and approved for publication.

\section{Acknowledgements}

The Ibadan Study of Ageing was funded by a grant from the Wellcome Trust.

\section{Author details}

${ }^{1}$ Department of psychiatry, College of Medicine, University of Ibadan, P.M.B 5017 (GPO) Ibadan, Nigeria. ${ }^{2}$ Department of Preventive Medicine and Primary Care, Faculty of Clinical Sciences, College of Medicine, University of Ibadan, P. M.B 5017 (GPO) Ibadan, Nigeria.

Received: 2 November 2012 Accepted: 25 February 2013

Published: 13 March 2013

\section{References}

1. De Leo D, Burgis S, Bertolote JM, et al: Definitions of suicidal behaviour. In Suicidal behaviour; Theories and research findings. Edited by De Leo D, BilleBrahe U, Kerkhof A, et al. Cambridge: Hogrefe \& Huber; 2004:17-40.

2. Jamison KR: In Night Falls Fast: Understanding Suicide. Edited by Alfred K. New York; 1999.

3. World Health Organization: World report on violence and health. Geneva: WHO; 2002

4. Mello-Santos C, Bertolote JM, Wang YP: Epidemiology of suicide in Brazil (1980-2000): characterization of age and gender rates of suicide. Rev Bras Psiquiatr 2005, 27:131-134.

5. The National Survey on Drug Use and Health (NSDUH) report, 2009. Suicidal Thoughts and Behaviours among Adults. http://oas.samhsa.gov/.

6. Lapierre S, Erlangsen A, Waern M, De Leo D, Oyama H, Scocco P, Gallo J, Szanto K, Conwell Y, Draper B, Quinnett P, International Research Group for Suicide among the Elderly: A systematic review of elderly suicide prevention programs. Crisis 2011, 32(2):88-98.

7. Shah A, Bhat R, Mackenzie S, Koen C: Elderly Suicide rates: cross-national comparison of trends over a 10 years period. International Psychogeriatrics 2008, 20:673-678

8. Abraham VJ, Abraham S, Jacob KS: Suicide in the elderly in Kaniyambadi block, Tamil Nadu, South India. Int J Geriatr Psychiatry 2005, 20(10):953-955.

9. Conwell $Y$, Duberstein PR, Connor $K$, et al: Access to firearms and risks for suicide in middle-aged and older adults. Am J Geriatr Psychiatry 2002, 10:16-407.

10. Beck AT, Brown G, Steer RA, et al: Suicide ideation at its worst point: a predictor of eventual suicide in psychiatric outpatients. Suicide Life Threat Behav 1999, 29:1-9.

11. Lapierre S, Boyer R, Desjardins S, Dube M, Lorrain D, Preville M, Brassad J: Daily hassles, physical illness, and sleep problems in older adult with wish to die. International Psychogeriatrics 2012, 24(2):243-245.

12. Conwell $Y$ : Suicide in later life: a review and recommendations for prevention. Suicide and Life-Threatening Behaviour 2001, 31(Suppl):32-47.
13. Ayalon $\mathrm{L}$, Litwin $\mathrm{H}$ : What cognitive functions are associated with passive suicidal ideation? Finding from a national sample of community dwelling isrealis. Int J Geriatr Psychiatry 2009, 24:472-478.

14. Conwell Y, Duberstein PR, Cox C, Hermann J, Forbes N, Caine ED: Age differences in behavior leading to completed suicide. American Journal of Geriatric Psychiatry 1998, 6:122-126.

15. Kjolseth I, Ekeberg $\mathrm{O}$ : When elderly people give warning of suicide. International Psychogeriatrics 2012, 24(9):1393-1401.

16. Gureje $O$, Ogunniyi S, Kola L, Afolabi E: Functional disability among elderly Nigerians: results from the Ibadan Study of Ageing. J Am Geriatr Soc 2006, 54(11):1784-1789.

17. Gureje $\mathrm{O}$, Kola L, Afolabi E: Epidemiology of major depressive disorder in elderly Nigerians in the Ibadan Study of Ageing: a community-based survey. Lancet 2007, 370(9591):64-957.

18. Kish L: A Procedure for Objective Respondent Selection within the Household. J Am Stat Assoc 1949, 44(247):380-387.

19. Kessler RC, Ustun TB: The World Mental Health (WMH) Survey Initiative Version of the World Health Organization (WHO) Composite International Diagnostic Interview (CIDI). International Journal of Methods Psychiatric Research 2004, 13:93-121.

20. American Psychiatric Association: DSM-IV: Diagnostic and Statistical Manual of Mental Disorders. 4th edition. Washington DC: American Psychiatric Association; 1994.

21. Ferguson BD, Tandon A, Gakidou $\mathrm{E}$, et al: Estimating permanent income using indicator variables. In Health Systems Performance Assessment: Debates, Methods and Empiricism. Edited by Murray CJL, Evans DB. Geneva: World Health Organization; 2003:747-760.

22. StataCorp: Stata Statistical Software, version 7.0 for windows. Texas, Stata, College Station; 2001.

23. Hosmer DW, Lemeshow S: Applied logistic regression. New York: John Wiley \& Sons; 2000.

24. Oladeji BD, Gureje O: Parental mental disorders and suicidal behaviour in the Nigerian survey of mental health and well-being. Arch Suicide Res 2011, 15(4):83-372.

25. Corna LM, Cairney J, Streiner DL: Suicide ideation in older adults: Relationship to mental health problems. Gerontologist 2010, 50(6):785-795.

26. Cook JM, Pearson JL, Thompson T, Black BS, Rabins PV: Suicidality in Older African Americans: Findings from the EPOCH Study. Am J Geriatr Psychiatry 2002, 10(4):437-446.

27. Bernal M, Haro JM, Bernet S, Brugha T, de Graff R, et al: Risk factor for suicidality in Europe; result from ESEMED study. J Affect Disord 2007 101:27-34.

28. Scocco P, Meneghel G, Caon F, Buono M, De Leo D: Death ideation and its correlates: survey of an over-65-year-old population. J Nerv Ment Dis 2001, 189:210-218

29. O'Connell H, Chin AV, Cunningham C, et al: Recent developments: suicide in older people. BMJ 2004, 329:8-895

30. Vanlaere P, Bouckart F, Gartsman C: care for suicidal people: current clinical-ethical consideration. J med Ethics 2007, 33:376-381.

31. Yip PS, Chi I, Chiu H, Wai KC, Conwell Y, Caine E: A prevalence study of suicide ideation among older adults in Hong Kong SAR. Int J Geriatr Psychiatry 2003, 18:1056-1062.

32. Middleton N, Whitley E, Frankel S, Dorling D, Sterne J, Gunnell D: Suicide risk in small areas in England and Wales, 1991-1993. Soc Psychiatry Epidemiol 2004, 39:45-52.

33. Yip PSF, Callanan C, Yuen HP: Urban/rural and gender differentials in suicide rates: east and west. J Affect Disord 2000, 57:106-199.

34. Shah A, Bhat R, Zarate-Escudero S: Elderly Suicide rates: the importance of a non-linear relationship with distal risk and protective factors. International psychogeriatrics 2012, 25(9):1363-1367.

35. Préville M, Boyer R, Grenier S, et al: Scientific Committee of the ESA Study. The epidemiology of psychiatric disorders in Quebec older adult population Can J Psychiatry 32, 53(12):822.

36. Jorm A, Henderson A, Scott R, Korten A, Christensen H, Mackinnon A: Factors associated with the wish to die in elderly people. Age and Ageing 1995, 24:389-392.

doi:10.1186/1471-244X-13-80

Cite this article as: Ojagbemi et al: Suicidal behaviour in old age results from the Ibadan study of ageing. BMC Psychiatry 2013 13:80. 